\title{
Influência do fotoperíodo no consumo alimentar, produção e composição do leite de ovelhas Bergamácia
}

\author{
Cristiane Otto de Sá(1), Edson Ramos de Siqueira(2), José Luiz de Sá(1) e Simone Fernandes ${ }^{(2)}$
}

\begin{abstract}
(1)Embrapa Semi-Árido, BR 428, Km 152, Caixa Postal 23, CEP 56302-970 Petrolina, PE. E-mail: cris@cpatc.embrapa.br, sa@cpatc.embrapa.br (2)Universidade Estadual Paulista, Fac. de Medicina Veterinária e Zootecnia, Dist. Rubião Júnior, s/noo, CEP 18618-000 Botucatu, SP. E-mail: ersiqueira@fca.unesp.br
\end{abstract}

\begin{abstract}
Resumo - O objetivo deste trabalho foi avaliar o efeito do fotoperíodo sobre o consumo alimentar, produção e composição do leite (gordura, proteína, lactose, sólidos totais) e número de células somáticas de sete ovelhas da raça Bergamácia, submetidas a um fotoperíodo considerado curto (12 horas luz:12 horas escuro), e oito ovelhas da mesma raça, a um fotoperíodo longo (18 horas luz:6 horas escuro), durante as últimas quatro semanas de gestação e três meses de lactação. Para comparação, foi utilizado o teste t para duas amostras independentes. O consumo alimentar avaliado, diariamente, para cada baia com duas ovelhas, não diferiu entre os tratamentos. No fotoperíodo curto, o consumo médio diário foi de 4,48 kg e, no fotoperíodo longo, de 4,40 kg. Não foi observada diferença significativa entre os fotoperíodos, para a produção de leite e teores de proteína, lactose e sólidos totais, quando considerados os 84 dias de lactação. No fotoperíodo curto, a porcentagem média de gordura foi 5,57\%, índice superior ao obtido no fotoperíodo longo, de 5,21\%. Na análise dos resultados, a cada semana, notou-se que na segunda e na quarta semanas de lactação, a produção de leite foi maior nas ovelhas do fotoperíodo longo. O número de células somáticas não diferiu entre os fotoperíodos e manteve-se baixo por toda a lactação. O maior número de horas de luz estimula a produção de leite no primeiro mês de lactação, principalmente na quarta semana, e as porcentagens de gordura e sólidos totais são menores nos períodos de maior produção de leite.
\end{abstract}

Termos para indexação: ovino, luminosidade, lactação.

\section{Influence of photoperiod on food intake, milk yield and milk composition of Bergamasca ewes}

\begin{abstract}
The objective of this work was to evaluate the effect of photoperiod on food intake, and milk production and composition (fat, protein, lactose, total solids) and somatic cell number. Seven Bergamasca ewes were submitted to a short photoperiod (12 hours light:12 hours dark), and eight Bergamasca ewes were submited to a long photoperiod (18 hours light:6 hours dark), during the last four weeks of pregnancy, and for three months of lactation. Results were compared by t test for two independent samples. Food intake was evaluated daily for each pen containing two ewes, and did not differ between treatments. Mean food intake was $4.48 \mathrm{~kg}$ under the short photoperiod, and was $4.40 \mathrm{~kg}$ under the long photoperiod. Differences between photoperiods were not significant for milk production and levels of protein, lactose and total solids considering 84 days of lactation. Mean percentage fat of $5.57 \%$ for the short photoperiod was greater than that $5.21 \%$ for the long photoperiod. In weekly results analyses, it was observed that in the second and fourth week of lactation, milk production of the ewes under long photoperiod was higher. Somatic cells number did not differ between photoperiods and stayed low during all lactation period. The greatest number of hours of light stimulated milk production in the first month of lactation, mainly in fourth week. Percentages of fat and total solids are lower in periods of greater milk production.
\end{abstract}

Index terms: sheep, light, lactation.

\section{Introdução}

O interesse em estudar e pesquisar a produção e a composição do leite de pequenos ruminantes tem aumentado nos últimos anos, em razão das mudanças ocorridas nos sistemas de produção (Fuente et al., 1997). A intensificação na produção, tanto de ovinos quanto de caprinos, permite uma oferta constante de alimentos ao longo do ano, e um manejo mais eficiente, o que torna possível criar animais com aptidão leiteira (Cavani et al., 1991).

A produção de leite ovino é uma atividade relativamente nova em alguns países, tais como a Austrália e a Nova Zelândia, onde as informações sobre a criação de 
ovinos de leite são raras. Mesmo em países cuja produção de leite é uma tradição de muitos anos, há uma deficiência de novas tecnologias e trabalhos científicos ligados à produção de leite ovino. Entretanto, é de conhecimento geral que o leite apresenta características que permitem transformá-lo em produtos de elevado valor comercial, como queijos e iogurtes (Bencini \& Pulina, 1997; Pugliese et al., 2000).

No Brasil, a produção de leite ovino é uma atividade pouco conhecida, embora existam animais de raças com aptidão leiteira, como é o caso da Bergamácia. Segundo Knight et al. (1993), uma das formas mais acessíveis para se formar um rebanho leiteiro é a seleção de ovelhas nacionais que apresentam uma alta produção leiteira, e o cruzamento das mesmas com machos de raças com aptidão para a produção de leite. Para tanto, é necessário conhecer a quantidade e a qualidade do leite produzido pelas fêmeas das diferentes raças.

Existem vários fatores que interferem na quantidade e na qualidade do leite produzido, estudados e descritos por diferentes autores (Peeters et al., 1992; Sakul \& Boylan, 1992; Knight et al., 1993; Hassan, 1995; Simos et al., 1996; Bencini \& Pulina, 1997; Fuertes et al., 1998). Entre esses fatores estão a raça, a idade da ovelha, o estágio da lactação, o número de cordeiros, as técnicas de ordenha, o estado sanitário e infecções de úbere, o manejo do rebanho, o nível nutricional, durante a gestação e lactação, e a luminosidade.

O ovino sofre influência acentuada do fotoperíodo, com relação aos aspectos produtivos e reprodutivos. $\mathrm{O}$ aumento da luminosidade à qual o animal é exposto pode, em determinadas situações, elevar o ganho de peso (Eisemann et al., 1984), a produção de leite (Kann, 1997) e o crescimento da lã (Butler, 1994). Entretanto, à medida que a luminosidade aumenta, diminui a ocorrência de cios e a fertilidade fica prejudicada, principalmente em raças ovinas mais estacionais. A natureza busca um equilíbrio entre os aspectos reprodutivos e produtivos do ovino, visando a sua sobrevivência, porém é possível manipular-se a luminosidade, para se obter um melhor desempenho do animal (Eisemann et al., 1984).

A nutrição e a luminosidade têm grande influência sobre os hormônios envolvidos na lactação. Portanto, é de se esperar que períodos de maior luminosidade estimulem a produção de leite. Reksen et al. (1999), ao estudar o efeito do fotoperíodo na produção de vacas leiteiras, observaram que a utilização de iluminação, no período da noite, aumentou a produção de leite e, por ser um trabalho com fêmeas bovinas, a fertilidade também melhorou com o maior número de horas luz. Bocquier et al. (1997) observaram que ovelhas expostas a um fotoperíodo longo tiveram uma produção de leite $25,3 \%$ maior do que as ovelhas expostas a um fotoperíodo curto, durante uma lactação de 150 dias. Entretanto existem divergências, e o mecanismo pelo qual a luminosidade pode influenciar na produção e na qualidade do leite, não é bem conhecido (Bocquier et al., 1997; Reksen et al., 1999).

Este trabalho teve como objetivo avaliar o efeito do fotoperíodo sobre o consumo alimentar, produção, composição e sobre o número de células somáticas do leite de ovelhas, da raça Bergamácia.

\section{Material e Métodos}

O trabalho foi desenvolvido na Faculdade de Medicina Veterinária e Zootecnia da Unesp, Campus de Botucatu, utilizando-se ovelhas da raça Bergamácia, com idades que variaram de 3 a 5 anos, e com peso médio de 63,11 kg, no início do experimento. O cio das ovelhas foi sincronizado, mediante a utilização de esponjas vaginais, contendo 60 mg de medroxiprogesterona, no início do mês de abril; as esponjas permaneceram nas fêmeas por um período de 14 dias. No dia da retirada, foram aplicadas 500 UI/ovelha de gonadotrofina coriônica de éguas prenhas (PMSG). O controle do cio foi realizado por meio de rufiões, com buçal marcador e, 48 horas após a aplicação do PMSG, as ovelhas foram inseminadas. Duas semanas após a inseminação, as fêmeas foram colocadas junto com o reprodutor, com a finalidade de assegurar o número necessário de fêmeas gestantes para o experimento. O diagnóstico de gestação por ultra-sonografia foi realizado aos 35 e 56 dias, após a inseminação. As fêmeas gestantes foram separadas e alimentadas, de acordo com as exigências nutricionais para ovelhas em início de gestação, segundo o National Research Council (1985).

Seis semanas antes do início dos partos, as ovelhas foram tosquiadas e transferidas para a câmara bioclimática, onde foram submetidas a tratamentos de luminosidade. Durante a quinta e a sexta semanas antes do parto, foi realizado um período de adaptação de 14 dias, quando as ovelhas foram expostas a um fotoperíodo de 12 horas luz:12 horas escuro. Na quarta semana antes do parto, 16 ovelhas foram separadas em dois grupos, equilibrando-se a idade, peso e escore corporal dos animais. Essas fêmeas receberam dois tratamentos, descritos a seguir. 
No primeiro tratamento, oito ovelhas foram submetidas, durante as últimas quatro semanas de gestação, e durante os meses de lactação, a um fotoperíodo considerado curto, de 12 horas luz:12 horas escuro. As luzes eram acesas às $6 \mathrm{~h}$ e apagadas às $18 \mathrm{~h}$ - fotoperíodo semelhante ao que ocorre naturalmente, na época de lactação das ovelhas. Uma ovelha desse tratamento foi retirada do experimento, por problemas no úbere, não relacionados com o trabalho, de modo que sobraram apenas sete animais. No segundo tratamento, oito ovelhas foram submetidas, durante as últimas quatro semanas de gestação, e durante os meses de lactação, a um fotoperíodo longo de 18 horas luz:6 horas escuro. As luzes eram acesas às $6 \mathrm{~h}$ e apagadas às 24h.

As ovelhas foram alimentadas de acordo com as exigências nutricionais para fêmeas em final de gestação e em lactação, segundo o National Research Council (1985).

A pesagem foi realizada no início do fotoperíodo (fase final da gestação) e no último dia da lactação (91 dias após o parto).

Durante a fase de lactação, foi avaliado o consumo, mediante a pesagem da alimentação fornecida e das sobras. As ovelhas receberam alimentação à vontade, nesse período, composta por uma relação concentrado:volumoso de $65: 35$, com 13,4\% de proteína bruta (PB) e $65 \%$ de nutrientes digestíveis totais (NDT). O arraçoamento dos animais foi realizado às $10 \mathrm{~h}$, após a primeira ordenha do dia, e às 16h30, antes da segunda ordenha. Cada baia do galpão experimental continha duas ovelhas, considerandose como repetição a média da baia. Utilizaram-se quatro baias (quatro repetições) por tratamento.

Os cordeiros foram separados das mães 48 horas após o parto. A partir do terceiro dia de lactação, as ovelhas foram ordenhadas duas vezes ao dia (9h e 17h), com ordenhadeira mecânica. A produção de leite foi avaliada diariamente. Uma vez por semana, foram coletadas amostras de leite da ordenha da manhã, e da ordenha da tarde (partes iguais e misturadas), para avaliação da composição no que diz respeito aos teores de sólidos totais, gordura, proteína, lactose e número de células somáticas. A análise da composição do leite foi efetuada no equipamento infravermelho - Bentley 2000 -, e a contagem de células somáticas foi realizada no contador de células somáticas - Somacount 500 -, no Programa de Análise de Rebanhos Leiteiros do Paraná, da Associação Paranaense de Criadores de Bovinos da Raça Holandesa (APCBRH).
A comparação das médias foi feita pelo teste $t$, para duas amostras independentes, pelo procedimento "Ttest procedure” do programa SAS (SAS Institute, 1989), a $10 \%$ de probabilidade.

\section{Resultados e Discussão}

Em razão de as ovelhas terem sido mantidas confinadas durante o experimento, e apresentado uma produção de leite relativamente baixa, não foi observada perda de peso em nenhum dos tratamentos na fase de lactação, contrariamente ao que foi observado nos diferentes trabalhos (Tabela 1). Perda de peso foi observada por Izadifard \& Zamiri (1997), que estudaram a performance na lactação de raças de cauda gorda. No experimento de Godfrey et al. (1997), a variação no peso foi observada durante toda a lactação, e as maiores perdas ocorreram aos 21-28 dias após o parto.

Embora as ovelhas, submetidas ao fotoperíodo longo, tenham ficado expostas por mais tempo à luminosidade, as mesmas não foram estimuladas a consumir mais ração $(p>0,10)$ (Tabela 1). Bocquier et al. (1986) verificaram que ovelhas submetidas ao fotoperíodo longo apresentaram maior produção de leite, mesmo tendo consumido quantidade de alimento igual ao das ovelhas submetidas ao fotoperíodo curto. Dahl et al. (1997) constataram os mesmos resultados com vacas. Os autores sugerem que a luz pode influenciar na liberação de hormônios ou, então, na morfologia do epitélio intestinal, o que pode levar a uma alteração do metabolismo e a um melhor aproveitamento dos alimentos. Entretanto, de acordo com a revisão realizada por Forbes (1982), animais expostos a um maior período de luminosidade podem aumentar o consumo alimentar, seja pelo tempo maior em que $o$ alimento fica visível, seja pelo aumento das exigências nutricionais, em conseqüência de uma maior produção estimulada pela luz.

Tabela 1. Peso das ovelhas no início (1-2 semanas antes do parto) e no fim do experimento (84 dias de lactação), e consumo alimentar médio diário por baia com duas ovelhas, durante a lactação (84 dias), de acordo com o fotoperíodo curto (FC) e longo (FL) $)^{(1)}$.

\begin{tabular}{lcccc}
\hline Variável & FC & FL & CV $(\%)$ & Prob $>$ ITI \\
\hline Peso vivo inicial $(\mathrm{kg})$ & $58,03 \pm 9,97$ & $64,60 \pm 9,28$ & 15,61 & 0,2090 \\
Peso vivo final $(\mathrm{kg})$ & $68,19 \pm 6,90$ & $75,01 \pm 10,93$ & 12,93 & 0,1791 \\
Consumo alimentar $(\mathrm{kg})$ & $4,48 \pm 0,33$ & $4,40 \pm 0,21$ & 6,29 & 0,7082 \\
\hline
\end{tabular}

${ }^{(1)}$ Os dados representam médias \pm desvio-padrão; CV: coeficiente de variação. 
A produção total de leite e a produção média diária encontram-se na Tabela 2. Embora se note uma maior produção das ovelhas do tratamento 2 , a diferença entre os tratamentos não foi significativa $(p>0,10)$. As ovelhas utilizadas nesse experimento não formavam um lote homogêneo com relação à idade ou ao número de lactações, portanto o coeficiente de variação foi elevado, o que contribuiu para a não significância obtida pelo teste empregado. Porém, diante da falta de conhecimento sobre as características leiteiras da raça Bergamácia, em conseqüência da escassez de animais dessa raça, no Brasil, os dados obtidos com relação à produção são importantes, apesar da grande variação individual do lote. No experimento realizado por Bocquier et al. (1990), foi observado que o fotoperíodo não influenciou na produção de leite, e de gordura do leite, no primeiro mês de lactação. Com relação aos valores para produção média diária de leite obtidos no presente trabalho, observa-se que não são médias consideradas altas para animais com aptidão leiteira. Outros trabalhos registram médias que variam de $400 \mathrm{~g}$ a $3 \mathrm{~kg}$ de leite produzidos por dia (Peeters et al., 1992; Sakul \& Boylan, 1992; Hassan, 1995; Izadifard \& Zamiri, 1997; Fuertes et al., 1998). Porém, é necessário salientar que os animais da raça Bergamácia, encontrados no Brasil, não foram selecionados para a produção de leite, embora a raça apresente essa aptidão, e tampouco são ovelhas acostumadas a serem ordenhadas mecanicamente.

Tabela 2. Produção total, produção diária e composição do leite, de acordo com o fotoperíodo curto (FC) ou longo (FL), durante 77 dias de lactação (desconsiderando-se a primeira semana de lactação) ${ }^{(1)}$.

\begin{tabular}{lcccc}
\hline Variável & FC & FL & CV $(\%)$ & Prob>ITI \\
\hline Produção total $(\mathrm{kg})$ & $38,95 \pm 9,18$ & $47,23 \pm 20,76$ & 37,97 & 0,3490 \\
Produção diária $(\mathrm{g})$ & $505,83 \pm 119,24$ & $613,35 \pm 269,66$ & 37,97 & 0,3490 \\
Teor (\%) & & & & \\
$\quad$ Gordura & $5,57 \pm 0,39$ & $5,21 \pm 0,18$ & 5,49 & 0,0366 \\
Proteína & $4,94 \pm 0,30$ & $4,90 \pm 0,29$ & 5,94 & 0,8011 \\
Lactose & $4,91 \pm 0,11$ & $4,91 \pm 0,08$ & 2,00 & 0,9835 \\
$\quad$ Sólidos totais & $16,63 \pm 0,53$ & $16,21 \pm 0,43$ & 2,92 & 0,1181 \\
Gordura & & & & \\
Produção total $(\mathrm{g})$ & $2.174,86 \pm 582,79$ & $2.432,80 \pm 1093,28$ & 38,69 & 0,5869 \\
$\quad$ Produção diária $(\mathrm{g})$ & $28,24 \pm 7,57$ & $31,45 \pm 14,29$ & 39,00 & 0,6053 \\
Proténa & & & & \\
Produção total $(\mathrm{g})$ & $1.921,18 \pm 497,90$ & $2.276,99 \pm 933,76$ & 36,20 & 0,3846 \\
$\quad$ Produção diária $(\mathrm{g})$ & $24,94 \pm 6,47$ & $29,41 \pm 12,21$ & 36,52 & 0,4038 \\
Lactose & & & \\
$\quad$ Produção total $(\mathrm{g})$ & $1.917,14 \pm 461,13$ & $2.331,33 \pm 1.050,70$ & 38,92 & 0,3538 \\
$\quad$ Produção diária $(\mathrm{g})$ & $24,90 \pm 5,99$ & $30,12 \pm 13,75$ & 39,29 & 0,3705 \\
Sólidos totais & & & & \\
Produção total $(\mathrm{g})$ & $6.485,01 \pm 1609,87$ & $7.604,49 \pm 3.330,55$ & 37,81 & 0,4337 \\
Produção diária $(\mathrm{g})$ & $84,22 \pm 20,91$ & $98,25 \pm 43,56$ & 38,14 & 0,4521 \\
\hline
\end{tabular}

(1)Os dados representam médias \pm desvio-padrão; CV: coeficiente de variação.
Embora não tenha sido possível detectar diferença entre os tratamentos, com relação à lactação como um todo, analisando-se os resultados a cada semana, notase que na segunda e na quarta semanas de lactação, as diferenças entre os tratamentos são consideráveis $(p<0,10)$ (Figura 1). Essa diferença entre os tratamentos foi diminuindo após a quinta semana e, na nona semana de lactação, a produção de leite ficou praticamente igual nos dois fotoperíodos. Embora a diferença de horas luz tenha sido mantida durante o final da gestação e toda a lactação, parece que o efeito da luz só foi evidente no primeiro mês de produção. Segundo Bocquier et al. $(1990,1997)$, as maiores diferenças na produção de leite, entre os fotoperíodos longo e o curto, ocorrem nos primeiros 30 a 40 dias de lactação.

No fotoperíodo longo, o pico de lactação ocorreu na quarta semana, mas no fotoperíodo curto foi observado bem mais tarde, na nona semana. Esse período de pico é variável entre os diferentes trabalhos. Bencini \& Pulina (1997) citam que o pico de produção ocorre entre a terceira e a quinta semanas da lactação. Boujenane \& Lairini (1992) verificaram que as raças Sardi, D'man e seus cruzamentos apresentaram o pico de produção na primeira semana de lactação; Hassan (1995) constatou que o pico de lactação, para raças de alta produção leiteira, pode ocorrer mais tarde, em torno da sétima semana após o parto.

Em ambos os tratamentos, a ordenha da manhã produziu mais leite do que a ordenha da tarde (Tabela 3, Figura 1). Isto é comum, quando os intervalos entre as ordenhas são diferentes (Simos et al., 1996; Fuente et al., 1997).

Considerando-se a produção de gordura, proteína, lactose e sólidos totais, durante toda a lactação, não foram observadas diferenças entre os tratamentos, com exceção da porcentagem de gordura (Tabela 2). No fotoperíodo curto, a porcentagem média de gordura foi superior à obtida no fotoperíodo longo. Há uma correlação negativa entre a produção e a composição do leite. Por isso, quando as ovelhas produzem mais leite, as concentrações de gordura e proteína diminuem. Em Hassan (1995), à medida que a produção de leite diminuía ao longo da lactação, os teores de gordura e sólidos totais aumentavam. Neste trabalho, a porcentagem de gordura foi, similarmente, menor no fotoperíodo longo, que apresentou uma maior produção de leite na segunda e na quarta semana de lactação. 

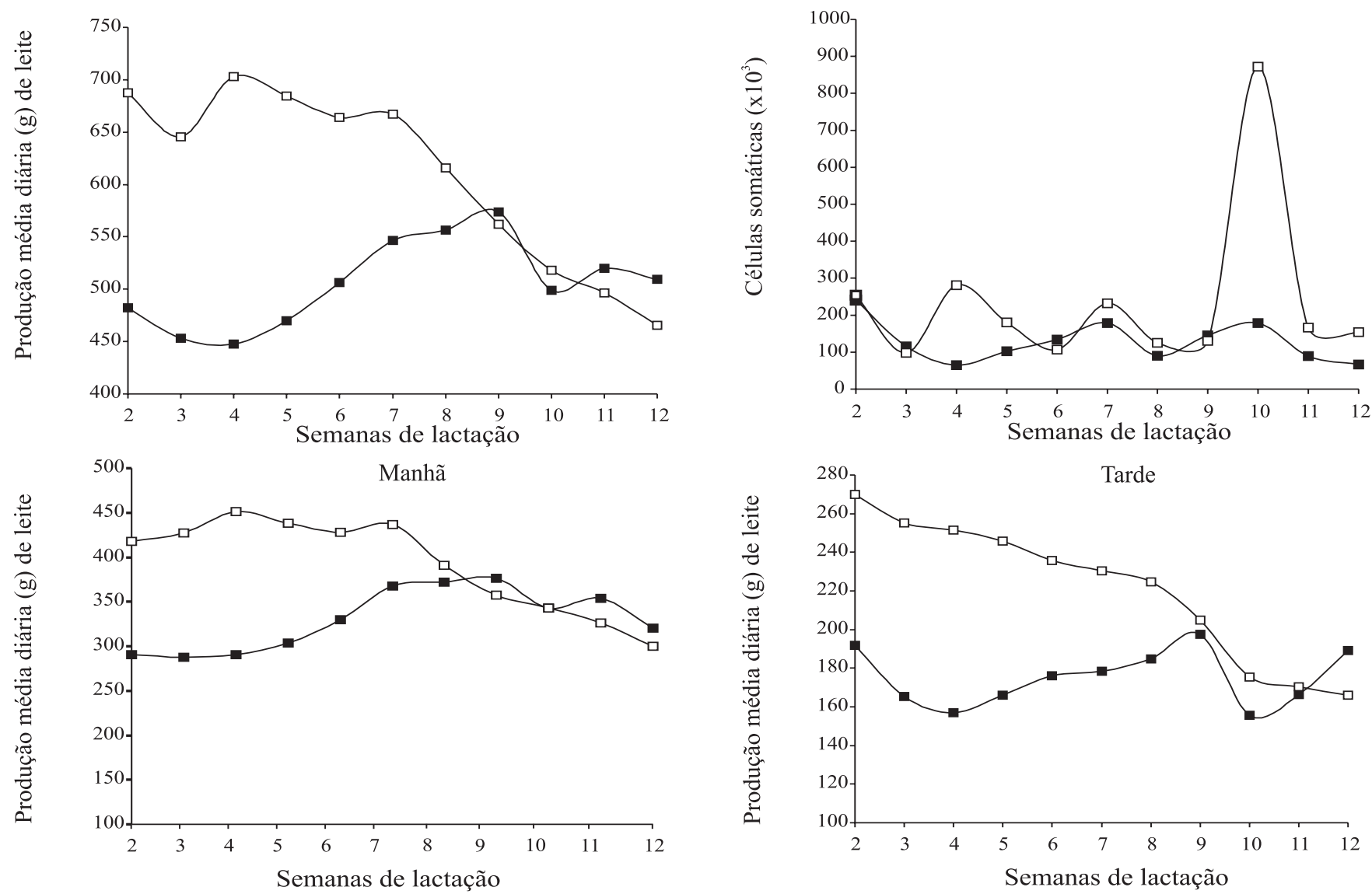

Figura 1. Curva da produção média diária de leite, do número de células somáticas e da produção média diária de leite de ovelhas, na ordenha da manhã e da tarde, no tratamento 1 ( $\boldsymbol{\square}, 12$ horas luz:12 horas escuro) e no tratamento 2 ( $\square$, 18 horas luz:6 horas escuro).

Tabela 3. Produção de leite de ovelhas, na ordenha da manhã e da tarde, de acordo com o fotoperíodo curto (FC) e longo (FL), durante 77 dias de lactação (desconsiderando-se a primeira semana de lactação) ${ }^{(1)}$.

\begin{tabular}{lclll}
\hline Variável & FC & \multicolumn{1}{c}{ FL } & CV $(\%)$ & Prob>ITI \\
\hline Lactação $(\mathrm{kg})$ & & & & \\
Manhã & $25,444 \pm 5,80$ & $30,215 \pm 13,41$ & 37,87 & 0,4002 \\
$\quad$ Tarde & $13,504 \pm 3,42$ & $17,012 \pm 7,44$ & 38,61 & 0,2741 \\
\hline Média diária (g) & & & & \\
$\quad$ Manhã & $330,45 \pm 75,37$ & $392,40 \pm 174,12$ & 37,87 & 0,4002 \\
$\quad$ Tarde & $175,39 \pm 44,40$ & $220,95 \pm 96,70$ & 38,61 & 0,2741 \\
\hline
\end{tabular}

${ }^{(1)}$ Os dados representam médias \pm desvio-padrão; CV: coeficiente de variação.

Embora a porcentagem de gordura tenha sido menor no fotoperíodo longo, a produção foi igual entre os fotoperíodos, em função da maior produção de leite para o fotoperíodo longo (Figura 2). Tanto a porcentagem quanto a produção diária de proteína não diferiram entre os tratamentos, ao longo da lactação. Notou-se uma tendência para uma maior produção de proteína no fotoperíodo longo, entre a segunda e a sexta semanas de lactação, em função da maior produção de leite (Figura 2). Com relação à lactose, observou-se que as ovelhas expostas ao fotoperíodo longo, apresentaram uma maior produção diária de lactose na quarta semana, e uma porcentagem maior na segunda semana de lactação. Porém, quando a produção de leite diminuiu, na décima primeira semana de lactação, a porcentagem de lactose do tratamento 2 (fotoperíodo longo) passou a ser menor (Figura 2). Snowder \& Glimp (1991) observaram maior teor de lactose aos 28 dias, e redução do mesmo, ao longo da lactação. No que diz respeito aos sólidos totais, constatou-se uma relação inversa entre a produção e a porcentagem dos constituintes do leite. No fotoperíodo longo, a porcentagem de sólidos totais foi menor, quando comparada com o fotoperíodo curto, na quarta semana de lactação, mas a produção diária 
de sólidos totais foi maior, em função da maior produção de leite ocorrida nessa semana de produção (Figura 2).
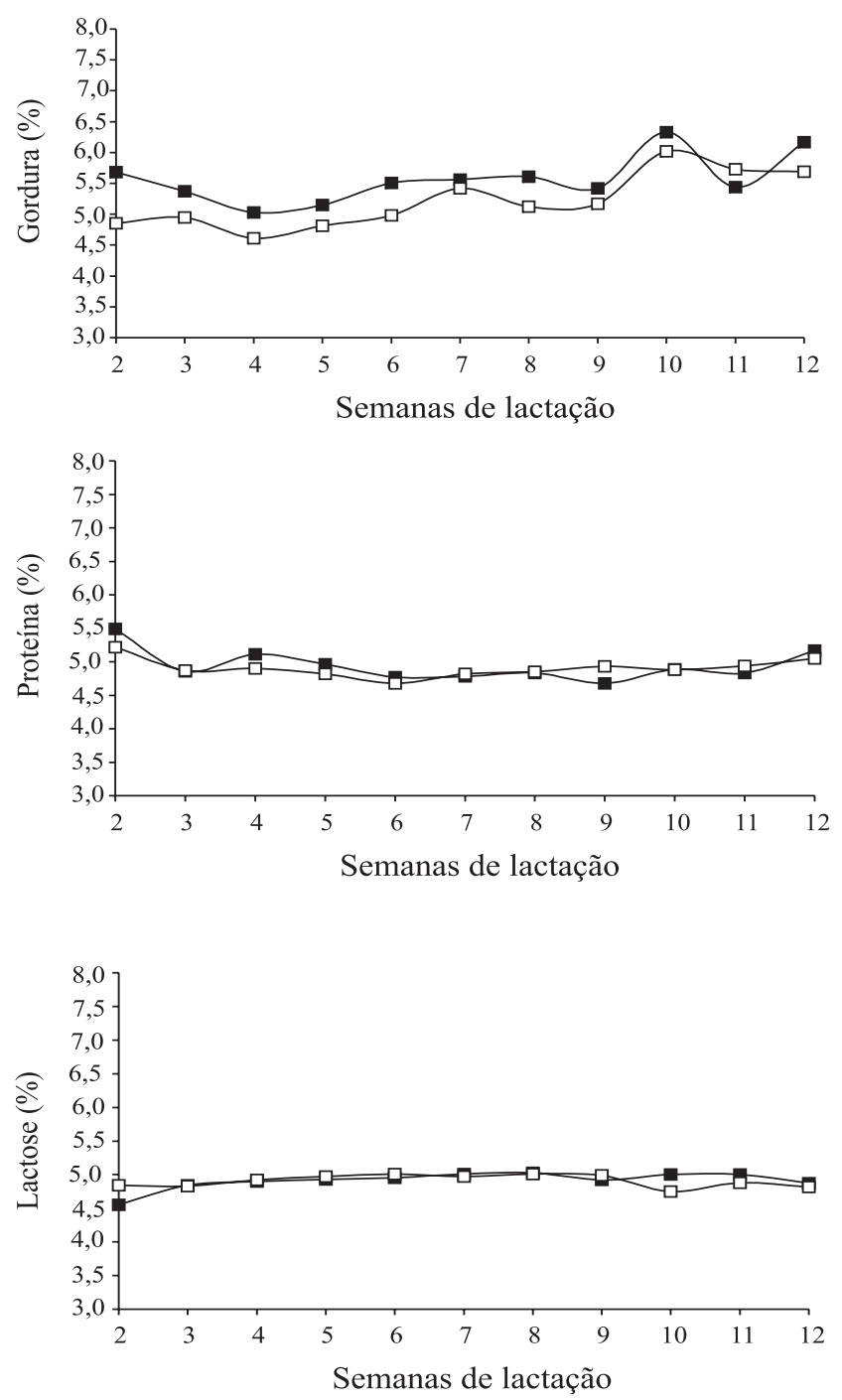

Sakul \& Boylan (1992) e Hassan (1995) compararam as curvas de lactação de diferentes raças ovinas e observaram que as porcentagens de gordura, proteína e
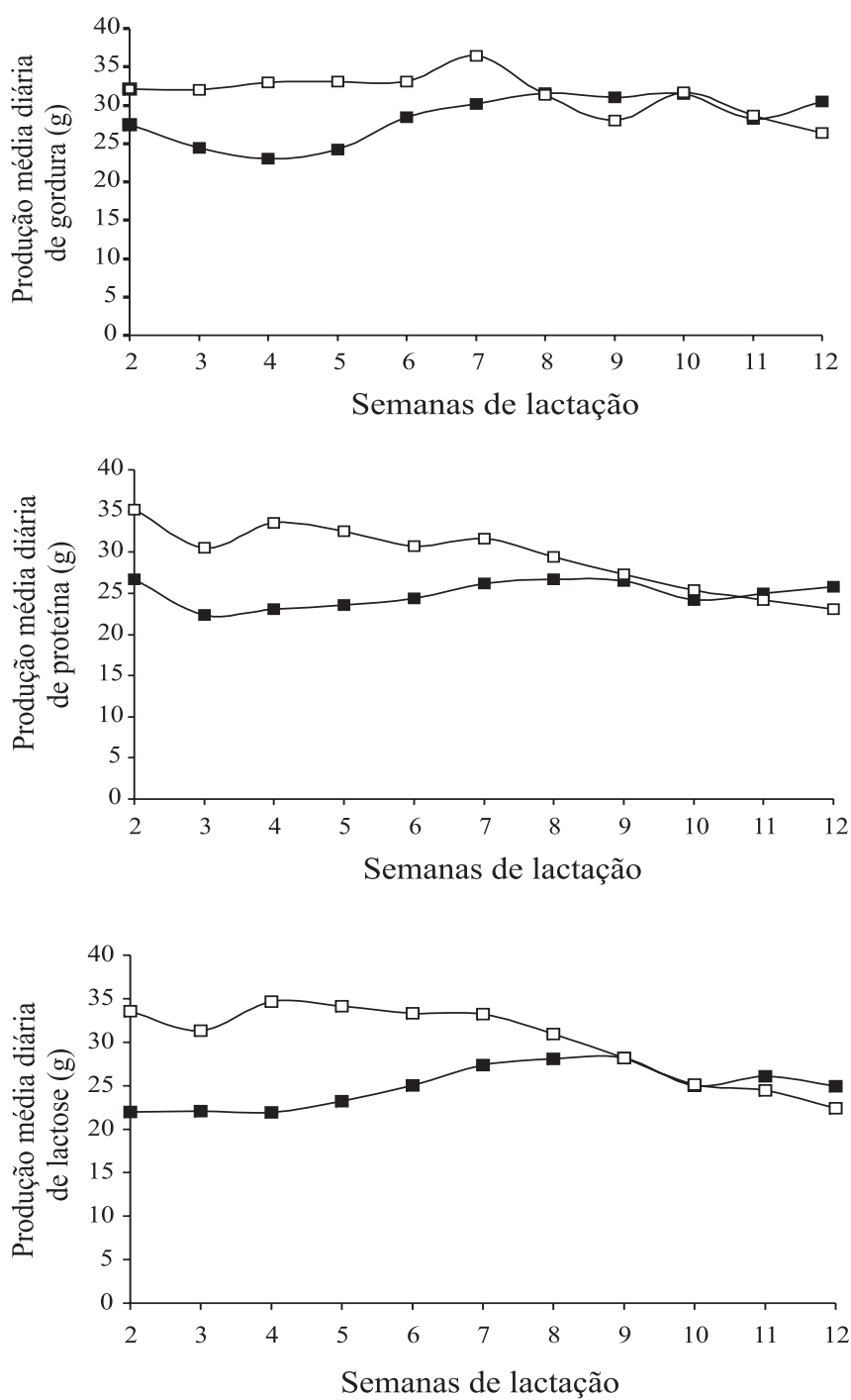

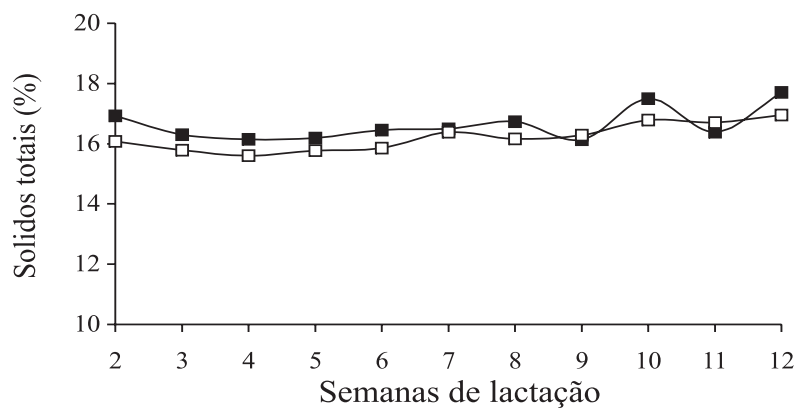

Figura 2. Curva da porcentagem e da produção média diária de gordura, proteína, lactose e sólidos totais, em ovelhas no tratamento 1 (घ,12 horas luz:12 horas escuro) e no tratamento 2 ( $\square$, 18 horas luz:6 horas escuro). 
sólidos totais aumentavam ao longo da lactação, enquanto a produção de leite diminuía, fato também observado neste trabalho e mais evidente para a porcentagem de gordura e sólidos totais, em ambos os tratamentos. Simos et al. (1996) obtiveram correlações negativas entre produção de leite e gordura; proteína e sólidos totais; gordura e lactose; sólidos totais e lactose.

Uma característica importante foi o elevado coeficiente de variação para a produção de leite, e o baixo coeficiente para as porcentagens de gordura, proteína, lactose e sólidos totais, o que foi igualmente observado por Knight et al. (1993) e Pugliese et al. (2000).

A contagem de células somáticas manteve-se baixa durante o experimento (Tabela 4). Verificou-se um aumento na contagem de células somáticas na décima semana, no fotoperíodo longo, observado em uma ovelha. Como na semana seguinte a contagem voltou aos níveis normais, é possível que o aumento não tenha sido causado por uma mastite subclínica e, sim, por uma situação de estresse que pode, momentaneamente, elevar o número de células somáticas (Figura 1). A saúde da ovelha e, em particular, a da glândula mamária, influencia na quantidade e na qualidade do leite produzido (Bencini \& Pulina, 1997; Pugliese et al., 2000). Comparando-se a contagem dessas células com Fuente et al. (1997) e Cavani et al. (1991), observa-se que a contagem de células somáticas permaneceu baixa neste trabalho, o que permite afirmar que problemas como a

Tabela 4. Log do número médio de células somáticas no leite de ovelhas, de acordo com o fotoperíodo curto (FC) ou longo (FL), até a décima segunda semana de lactação(1).

\begin{tabular}{lcccc}
\hline $\begin{array}{l}\text { Semana de } \\
\text { lactação }\end{array}$ & FC & FL & CV $(\%)$ & Prob>ITI \\
\hline Segunda & $5,28 \pm 0,29$ & $5,11 \pm 0,42$ & 7,09 & 0,3922 \\
Terceira & $4,99 \pm 0,25$ & $4,96 \pm 0,18$ & 4,31 & 0,7665 \\
Quarta & $4,79 \pm 0,17$ & $5,09 \pm 0,19$ & 8,25 & 0,1818 \\
Quinta & $4,99 \pm 0,16$ & $5,06 \pm 0,45$ & 6,95 & 0,6702 \\
Sexta & $5,07 \pm 0,27$ & $4,99 \pm 0,20$ & 4,70 & 0,5346 \\
Sétima & $5,18 \pm 0,27$ & $5,16 \pm 0,44$ & 7,20 & 0,8999 \\
Oitava & $4,93 \pm 0,16$ & $4,95 \pm 0,47$ & 7,29 & 0,8959 \\
Nona & $5,09 \pm 0,28$ & $5,04 \pm 0,28$ & 5,51 & 0,7554 \\
Décima & $5,10 \pm 0,36$ & $5,53 \pm 0,70$ & 10,68 & 0,1695 \\
Décima primeira & $4,86 \pm 0,28$ & $5,11 \pm 0,31$ & 5,87 & 0,1240 \\
Décima segunda & $4,79 \pm 0,18$ & $5,08 \pm 0,35$ & 5,78 & 0,0688 \\
\hline
\end{tabular}

(1)Os dados representam médias \pm desvio-padrão; CV: coeficiente de variação. mastite subclínica não afetaram os resultados relacionados com a produção e a qualidade do leite. Fuertes et al. (1998) obtiveram uma contagem média de células somáticas de $229 \times 10^{3}$, semelhante à deste trabalho, e considerada mais baixa do que a contagem encontrada na maioria dos rebanhos leiteiros submetidos a um programa de controle de mastite.

\section{Conclusões}

1. A maior produção de leite é evidente na segunda e na quarta semanas de lactação, nas ovelhas expostas ao fotoperíodo longo.

2. Na segunda e na quarta semanas de lactação, a porcentagem de gordura é menor nas ovelhas expostas ao fotoperíodo longo, porém a produção de gordura não diminui em razão da maior produção de leite.

3. A porcentagem de sólidos totais é menor na quarta semana de lactação, e a produção desse componente não diminui em função da maior produção de leite.

4. O consumo alimentar não é influenciado pela luminosidade.

5. O número de células somáticas, no leite das ovelhas, não é influenciado pela luminosidade e mantém-se baixo, durante toda a lactação, em razão da higiene na ordenha.

\section{Referências}

BENCINI, R.; PULINA, G. The quality of sheep milk: a review. Wool Technology and Sheep Breeding, v.45, p.182-220, 1997.

BOCQUIER, F.; KANN, G.; THERIEZ, M. Relationships between secretory patterns of growth hormone, prolactin and body reserves and milk yield in dairy ewes under different photoperiod and feeding conditions. Animal Production, v.51, p.115-125, 1990.

BOCQUIER, F.; LIGIOS, S.; MOLLE, G.; CASU, S. Effect of photoperiod on milk yield, milk composition and voluntary feed intake in dairy ewes. Annales de Zootechnie, v.46, p.427-438, 1997.

BOCQUIER, F.; THERIEZ, M.; KANN, G.; DELOUIS, C. The effect of photoperiod on the partitioning of net energy between milk production and body reserves in milked ewes. Reproduction, Nutrition, Developpement, v.26, p.389-390, 1986.

BOUJENANE, I.; LAIRINI, K. Genetic and environmental effects on milk production and fat percentage in D'man and Sardi ewes and their crosses. Small Ruminant Research, v.8, p.207-215, 1992.

BUTLER, L.G. Fatores que afetam a resistência da mecha com particular referência a Tasmânia. Wool Technology and Sheep Breeding, v.42, p.213-220, 1994.

CAVANI, C.; BIANCONI, L.; MANFREDINI, M.; RIZZI, L.; ZARRI, M.C. Effects of a complete diet on the qualitative 
characteristics of ewe milk and cheese. Small Ruminant Research, v.5, p.273-284, 1991.

DAHL, G.E.; ELSASSER, T.H.; CAPUCO, A.V.; ERDMAN, R.A.; PETERS, R.R. Effects of a long daily photoperiod on milk yield and circulating concentrations of insulin-like growth factor-I. Journal of Dairy Science, v.80, p.2784-2789, 1997.

EISEMANN, J.H.; BAUMAN, D.E.; HOGUE, D.E.; TRAVIS, H.F. Influence of photoperiod and prolactin on body composition and in vitro lipid metabolism in wether lambs. Journal of Animal Science, v.59, p.95-104, 1984.

FORBES, J.M. Effects of lighting pattern on growth, lactation and food intake of sheep, cattle and deer. Livestock Production Science, v.9, p.361-374, 1982.

FUENTE, L.F.; SAN PRIMITIVO, F.; FUERTES, J.A.; GONZALO, C. Daily and between-milking variations and repeatabilities in milk yield, somatic cell count, fat, and protein of dairy ewes. Small Ruminant Research, v.24, p.133-139, 1997.

FUERTES, J.A.; GONZALO, C.; CARRIEDO, J.A.; SAN PRIMITIVO, F. Parameters of test day milk yield and milk components for dairy ewes. Journal of Dairy Science, v.81, p.13001307, 1998.

GODFREY, R.W.; GRAY, M.L.; COLLINS, J.R. Lamb growth and milk production of hair and wool sheep in a semi-arid tropical environment. Small Ruminant Research, v.24, p.77-83, 1997.

HASSAN, H.A. Effects of crossing and environmental factors on production and some constituents of milk in Ossimi and Saidi sheep and their crosses with Chios. Small Ruminant Research, v.18, p.165-172, 1995.

IZADIFARD, J.; ZAMIRI, M.J. Lactation performance of two Iranian fat-tailed sheep breeds. Small Ruminant Research, v.24, p.69-76, 1997.

KANN, G. Evidence for a mammogenic role of growth hormone in ewes: effects of growth hormone-releasing factor during artificial induction of lactation. Journal of Animal Science, v.75, p.25412549, 1997.
KNIGHT, T.W.; BENCINI, R.; HAACK, N.A.; DEATH, A.H. Effects of shearing on milk yields and milk composition in machinemilked Dorset ewes. New Zealand Journal of Agricultural Research, v.36, p.123-132, 1993.

NATIONAL RESEARCH COUNCIL. Nutrient Requirements of Sheep. $6^{\text {th }}$ ed. Washington, DC.: National Academy Press, 1985.112p.

PEETERS, R.; BUYS, N.; ROBIJNS, L.; VANMONTFORT, D.; ISTERDAEL, J.V. Milk yield and milk composition of Flemish Milksheep, Suffolk and Texel ewes and their crossbreds. Small Ruminant Research, v.7, p.279-288, 1992.

PUGLIESE, C.; ACCIAIOLI, A.; RAPACCINI, S.; PARISI, G.; FRANCI, O. Evolution of chemical composition, somatic cell count and renneting properties of the milk of Massese ewes. Small Ruminant Research, v.35, p.71-80, 2000.

REKSEN, O.; TVERDAL, A.; LANDSVERK, K.; KOMMISRUD, E.; BOE, K.E.; ROPSTAD, E. Effects of photointensity and photoperiod on milk yield and reproductive performance of Norwegian Red cattle. Journal of Dairy Science, v.82, p.810-816, 1999.

SAKUL, H.; BOYLAN, W.J. Evaluation of U.S. sheep breeds for milk production and milk composition. Small Ruminant Research, v.7, p.195-201, 1992.

SAS INSTITUTE (Cary, Estados Unidos). Statistical Analysis System: language and procedures. Version 6, Cary, 1989. 638p.

SIMOS, E.N.; NIKOLAOU, E.M.; ZOIOPOULOS, P.E. Yield, composition and certain physicochemical characteristics of milk of the Epirus mountain sheep breed. Small Ruminant Research, v.20, p.67-74, 1996.

SNOWDER, G.D.; GLIMP, H.A. Influence of breed, number of suckling lambs, and stage of lactation on ewe milk production and lamb growth under range conditions. Journal of Animal Science, v.69, p.923-930, 1991.

$\overline{\text { Recebido em } 18 \text { de setembro de } 2003 \text { e aprovado em } 7 \text { de janeiro de } 2005}$ 